\title{
Effect of Water Content, Void Ratio and Clay Content on Sand P-Wave Velocity
}

\author{
Magdi M. El-Emam ${ }^{1}$, Zahid H. Khan'1, Mohammad O. Amer ${ }^{1}$ \\ ${ }^{1}$ Department of Civil Engineering, College of Engineering, \\ American University of Sharjah, Sharjah, UAE \\ melemam@aus.edu
}

\begin{abstract}
The main purpose of the current research is to implement different Geophysical Techniques (GT) in measuring wave velocity at different soil properties. For this purpose, a number of 6-in-diameter specimens have been prepared with different soil properties for index tests. The objective of the small scale models is to study the variation of the compressional wave velocity with different soil parameters. Soil properties that are of high importance to the wave velocity are compaction efforts (void ratio, density, porosity), water content, soil grading size, soil clay content, and the addition of Portland cement. Specially acquired accelerometers are used to measure the P-wave velocity through the soil specimens after manually triggering mechanical waves. Sensitivity tests program is conducted to determine suitable specimen dimensions and the best and right method of attaching the accelerometers to the soil specimen. Index test results indicate that the $\mathrm{P}$-wave velocity decreases as the soil water content and degree of saturation increases up to certain threshold values, which itself increases with the compaction effort. In addition, the wave velocity becomes larger as the soil includes more fine contents. Finally, compressional wave velocity increased as the void ratio of the soil specimen decreased.
\end{abstract}

Keywords: Geophysical techniques, sand, Wave velocity, soil properties, accelerometers, strip footing.

\section{Introduction}

Geophysical Technique uses the mechanical wave spread through the solid and its characteristic velocities in order to determine stiffness, damping, and different layers thicknesses. Stiffness (k) and damping (c) that are measured using the Geophysical Technique represent small strain response of the soil [1]. Sirikarn [2] states that both P-and S-wave velocities increase with an increase in the soil density and effective stress and with the reduction in the soil porosity. Minsu and GyeChun [3] point out a relationship between the internal angle of friction and the shear wave velocity. However, they indicate that the void ratio (e), and the effective overburden pressure $\left(\sigma_{0}\right)$ should be included in any equation that correlates soil friction angle and wave velocity. In addition, they report $25 \%$ difference between values of friction angles predicted with shear wave velocity and those predicted using standard penetration test (SPT). Likewise, Ohkubo and Terasaki [4] provide various expressions trying to relate the seismic wave velocities to weight density, water content, permeability, modulus of elasticity, and the unconfined compressive strength.

A review of the current state of practice with respect to measurement and variation of soil stiffness reveals that fewer studies have considered the correlation between the wave velocity in soil and the stress applied from shallow foundation. In addition, Bender Element that is commonly used for wave measurement in soil due to its simplicity and relatively low cost was reported to be unsuitable for undisturbed or cemented materials $[5,6]$. Furthermore, there is a lack of laboratory studies required for establishing relations between physical properties of soil and its seismic properties, especially at low confining pressures which is equivalent to shallow depth. The shortage of such laboratory studies leads to a lack of understanding the effects of soil formation, degree of saturation, water content, void ratio, cementitious material, and compaction on seismic (P- and S-wave) properties of soils [7]. It is noted that the P-wave laboratory data collected for soils at low-pressure conditions appropriate to the near surface are sparse in the literature and information about both compressional and shear wave velocity measurements as a function of pressure at extremely low pressures representing the shallow subsurface is required. A research strategy to meet this goal is to develop laboratory experiments involving the measurement of $\mathrm{P}$-wave velocity at low pressures in compacted soil specimens. Therefore, a simple, easy to use, and cost efficient setup is developed in order to measure P-wave velocity in different sandy soil specimens with different properties. The main objectives of the current paper is to introduce the implementation of laboratory setup that is capable of making accurate measurements of P- 
wave velocity in soil specimens at different soil conditions and properties. Such soil properties are void ratio and water content.

\section{Material properties}

The current research was conducted in the Geotechnical Laboratory of the College of Engineering at the American University of Sharjah (AUS). A preliminary sensitivity study was conducted using a number of index tests in order to come up with a final test set-up that can be used for all index tests. The main purpose of the sensitivity analysis, at the early stage of the project, is to choose the right boundary conditions, right material type, and right dimensions of the test set-up. Sand obtained from Ras Al-Khaima (RAK), UAE, was used in the small index tests, after passing it through the $2 \mathrm{~mm}$ sieve size. A number of soil tests such as sieve analysis, modified proctor test, specific gravity, and plasticity index test were conducted, according to ASTM standards, to determine the physical properties of the sand. Modified sand from original RAK sand was obtained by passing the sand through $2 \mathrm{~mm}$ sieve. The grain size distribution of this sand is shown in Figure 14. The sand is classified as poorly graded sand (SP) with about 1\% fines according to the Unified Soil Classification System (USCS). The value of the coefficient of curvature $\left(\mathrm{C}_{\mathrm{c}}\right)$ is 1 , and the value of uniformity coefficient $\left(\mathrm{C}_{\mathrm{u}}\right)$ is 4.3 . The specific gravity of the sandy soil was found to be $\mathrm{G}_{\mathrm{s}}=2.71$. Results of direct shear test indicate that the angle of internal friction of the RAK original sand used as backfill is $\phi=49^{\circ}$. The angle of internal friction is found to be greater than $38^{\circ}$, conforming to the Unified Soil Classification System of well-graded Sand.

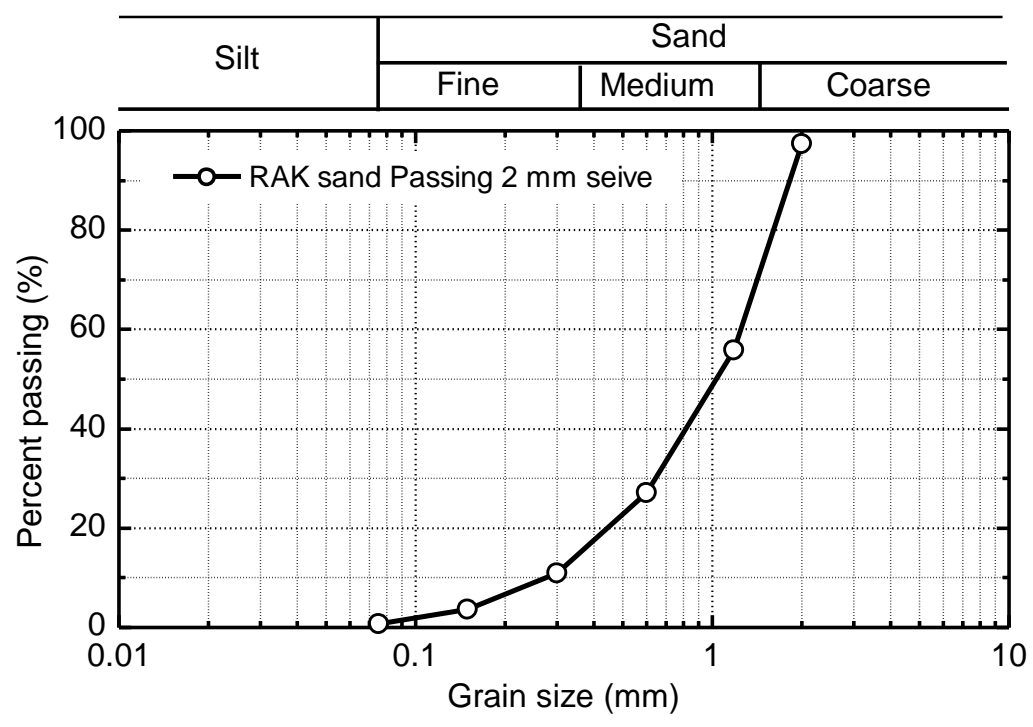

Fig. 1: Gradation for RAK sand after passing $2 \mathrm{~mm}$ sieve.

\section{Test Setup and Instrumentations}

\subsection{Test Setup}

A number of geophysical index tests have been conducted in order to come up with a final index test set-up that can be used for all index tests of the soil. A major objective of the sensitivity analysis is to select the right boundary conditions, and proper dimensions of the small index test set-up. Results of the sensitivity analysis which conducted at different specimen lengths, diameters, and different compaction efforts indicate that a sample length $\mathrm{L}=12.5 \mathrm{~cm}$ and diameter $\mathrm{D}=15 \mathrm{~cm}$ was the most suitable dimensions. These sample dimensions are selected to ensure that the wave length $\lambda$ is less than the sample half length (i.e. $\lambda<\mathrm{L} / 2$ ), and the near field distance NF is less than the radius of the specimen (i.e. $\mathrm{NF}<\mathrm{D} / 2$ ). In other words, to make sure that the waves are not interfering with the PVC cylindrical boundary of the specimen, the near field value NF should be less than the specimen radius. An average value of NF for 
typical specimen with $\mathrm{D}=15 \mathrm{~cm}$ and wave length $\lambda=0.4 \mathrm{~m}$ is calculated as $\mathrm{NF}=0.024 \mathrm{~m}$, which is much less than the radius of the specimen $(\mathrm{r}=0.075 \mathrm{~m})$.

Two accelerometers were attached to the sample both ends by using a group of elastic rubber bands. Moreover, each each accelerometer was attached to a circular steel plate to ensure that the accelerometers are well attached to the sample, and axis of motion is well aligned with the longitudinal axis of the cylindrical specimen. It is found that the axis of accelerometers cannot be adjusted if they are attached directly to the specimen without steel base plates, which works as a base for the accelerometers to perfectly rest on the sample sandy sides.

\subsection{Instrumentations and Sample Preparation}

The accelerometers used in this study are miniature accelerometers produced by DYTRAN Instruments, Inc., model $3006 \mathrm{~A}$ with a $12 \mathrm{~g}$ weight each, and $0.5 \mathrm{~cm}$ by $0.8 \mathrm{~cm}$ diameter and height. The accelerometers have $+50 \mathrm{~g}$ acceleration range, and $0.3 \mathrm{~Hz}$ to $5 \mathrm{kHz}$ frequency range with high resonant of $35 \mathrm{kHz}$. The accelerometers were eternally powered, and their output signals have been recorded using a two-channel Pico Scope produced by Pictech, which was connected to fast computer through a USB. In this research, for index tests, two accelerometers were attached to each specimen, as shown earlier, and were used to record sent and received signals. In addition, a steel spoon was used to hit the sensor in order to generate waves at the sender end. According to Marjanovic [8], accelerometers give high noise results compared to extensometers and ultrasonic P-wave transducers. Therefore, the measured response need to be treated before it could be used for analysis.

\subsection{Sample Preparation}

A number of 20 samples were prepared and tested, using the test setup shown in Fig. 1 and described earlier. All the samples were mixed with $6 \%$ by weight initial water content, as evaluated from proctor tests, and compacted into 5 layers using the modified hummer. In addition, all these samples were prepared using RAK-soil that passing 2 mm sieve. Moreover, all the samples were compacted into 5 layers using the modified hummer and the PVC mould. The protocol adopted for testing the first ten samples was the same, and the wave velocity was measured at six different timings as follows:

- Measured directly after sample preparation.

- Measured after the specimen is oven drying to lose incrementally $50 \mathrm{~g}$ of water.

- Measured after leaving the sample in air to cool down from the first heating.

- Fourth, fifth, and sixth measurements were after heating the sample in the oven where the sample's weight kept decreasing by an increment of approximately $50 \mathrm{~g}$. By that time, the soil specimen became fully dry.
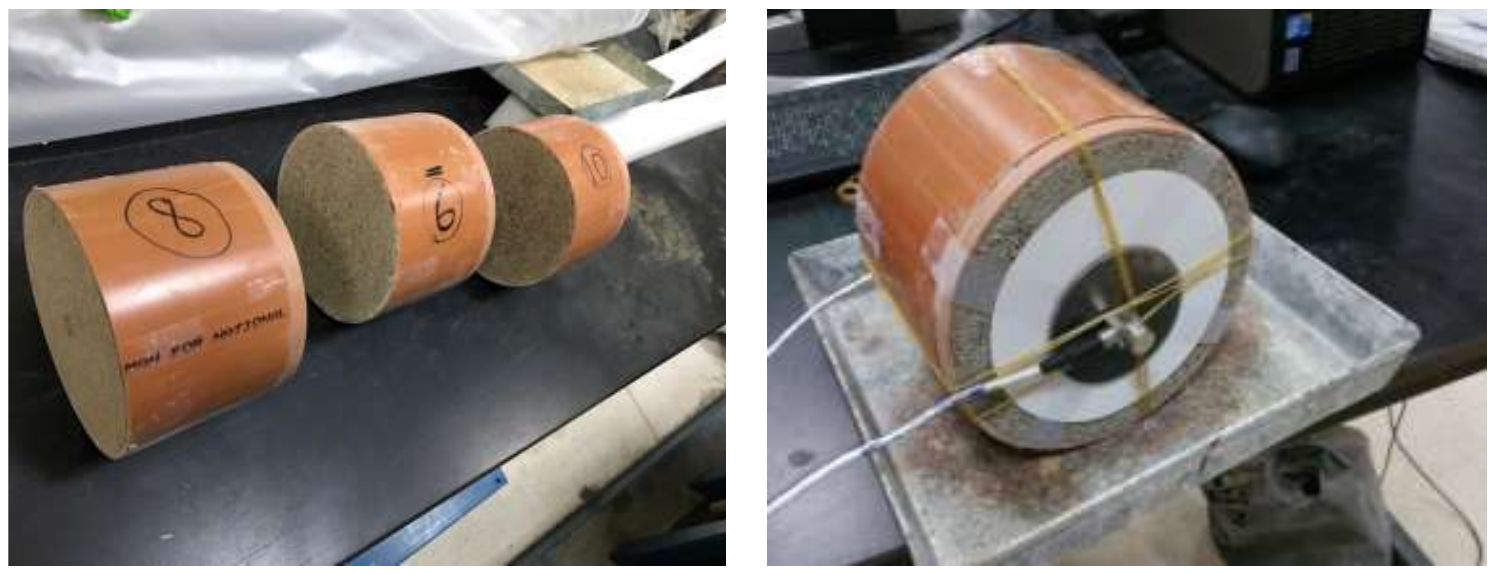

Fig. 2: Final set-up for index tests and a number of tested specimens. 


\section{Results and Discussions}

Waves were triggered by lightly hitting one of the accelerometers attached to the side of the sample (Fig. 2), and this accelerometer is designated as source. Then, the waves arrived to the other side of the sample were received and by a second accelerometer which is called a receiver. Fig. 3 shows a typical example of generated and received waves recorded with the two accelerometers attached to a soil specimen. Velocity was calculated by dividing length of the (i.e. distance travelled by the waves in soil specimen) by the time difference captured by the two accelerometers attached specimens at both sides. The arrival times of compression waves (P-waves) are estimated as the first deflection of the signals on time domain. In case of sinusoidal excitation, Jovicic et al. [9] suggest that the rising-to-rising travel time is defined as the time increment between the take-off of input signal to the first zero crossing point on the time domain of the output signal. The criteria employed to determine the travel times based on rise to rise of signals is used also by Suwal and Kuwano [10]. Fig. 2 show typical compression wave forms obtained in this study. The travel time is obtained by considering the time lag between the taking-off of the input signal and the taking-off of the output signal $(\Delta \mathrm{T})$.

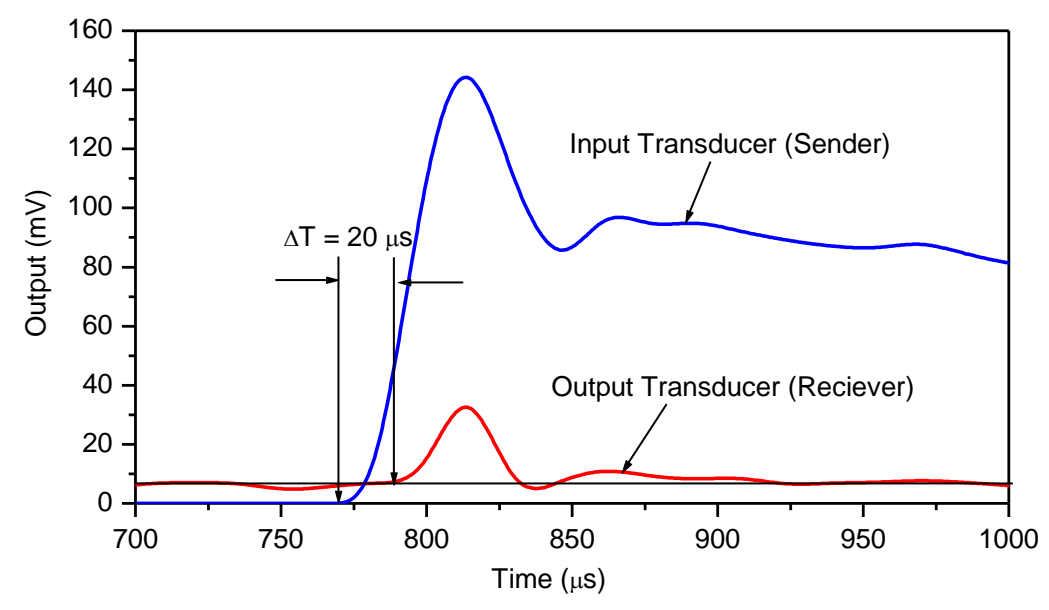

Fig. 3: Generated and received waves at both sides of the specimen.

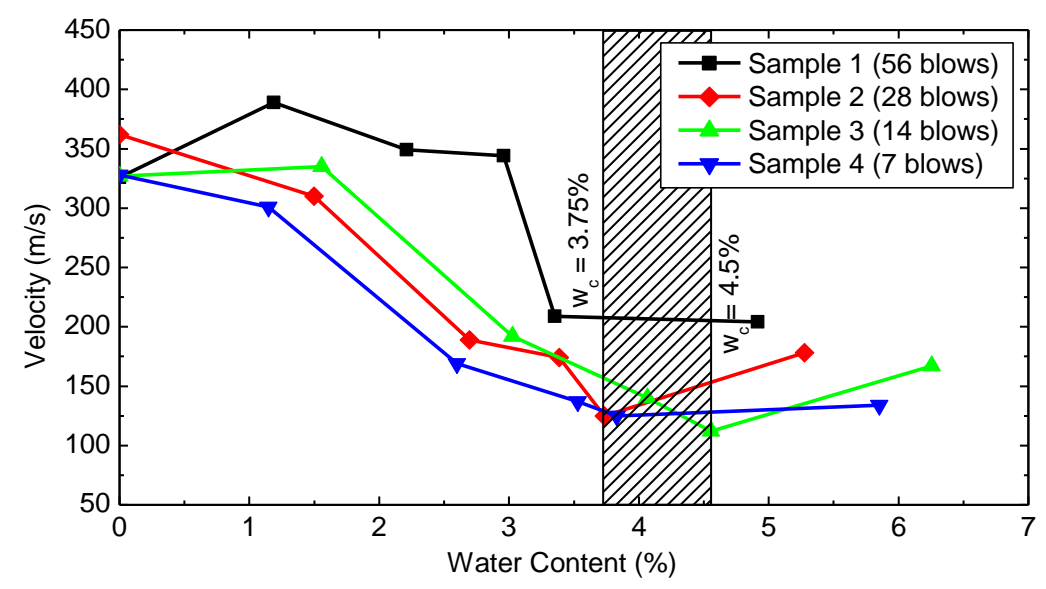

Fig. 4: variation of P-wave velocity with water content, at different compaction effort. 


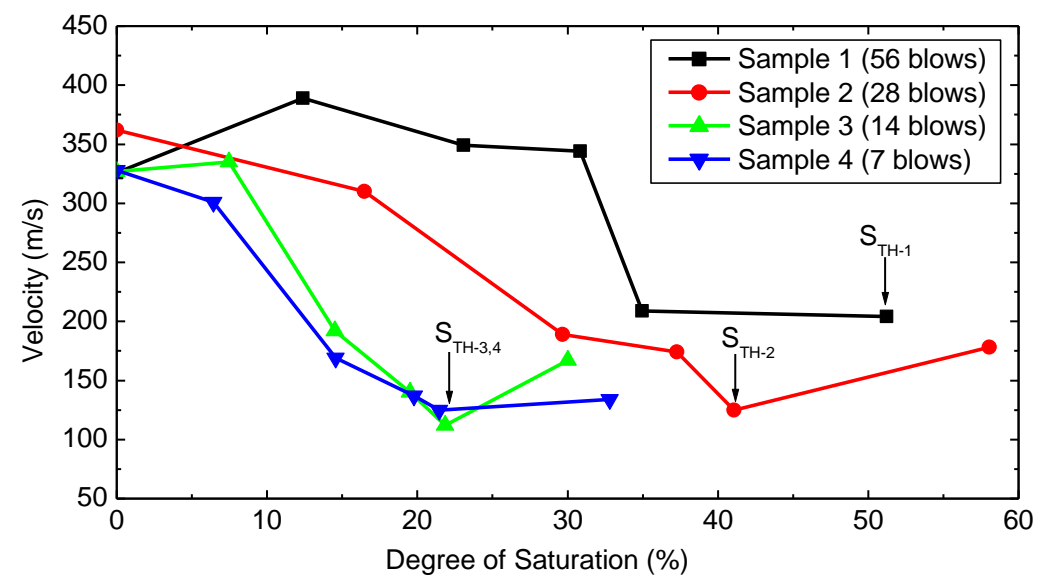

Fig. 5: Variation of P-wave velocity with degree of saturation.

\subsection{Effect of water Content}

Four samples are prepared of the same soil (i.e., soil passing $2 \mathrm{~mm}$ sieve size) and compacted at the same initial water content which is $\mathrm{w}=6 \%$. The main difference between the four samples is the compaction effort used during compaction, which are 56, 28, 14, and 7 blows/layer for samples 1,2,3, and 4, respectively. Different compaction effort is expected to produce soil specimens with different void ratio and different degree of saturation. Variations of P-wave velocity with water content percent, degree of saturations, and void ratio are shown in Figs. 4, 5, and 6 respectively. Figs. 4 and 5 indicate that the P-wave velocity decreases as the soil water content and degree of saturation increases, regardless of the degree of compaction used. It is well understood that the existence of water might increase the P-wave velocity, provided that the soil is fully saturated. In the current cases, the maximum degree of saturation is $58 \%$, attained by soil specimen 2 in Fig. 5, which is far below the $100 \%$ saturation. Although the P-wave velocity started to pick up again towards an increasing trend at degree of saturation of $58 \%$ for specimen 2, some other specimens started the trend of velocity increase at early values of degree of saturation, S. Fig. 5 indicates that $\mathrm{P}$ wave velocity started to increase with degree of saturation at $\mathrm{S}=22 \%$ for specimen 3 and 4 , and at $S=41 \%$ for specimen 2 . Values of degree of saturation where the velocity started to increase are called threshold values $\left(\mathrm{S}_{\mathrm{TH}}\right)$. Fig. 5 indicates that the threshold degree of saturation increases with the compaction effort (i.e. with decreasing void ratio). It could be concluded that the P-wave velocity decreases with increasing water content up to water content range of $3.75 \%$ to $4.5 \%$ (see Fig. 4). Once the water content value increases beyond this range, the wave velocity starts to increase.

\subsection{Effect of Compaction effort}

Both Figs. 4 and 5 indicate that compaction effort (i.e., degree of compaction) highly affects the measured P-wave velocity. At the same water content or same degree of saturation, the soil with high compaction effort shows high values of wave velocity compared to the soil with low compaction effort. For example, Fig. 5 indicates that, at degree of saturation $\mathrm{S}$ $=20 \%, V_{P}=361,275,135 \mathrm{~m} / \mathrm{s}$ for soil compacted with 56,28 , and 14 blows/layer, respectively. This result is clarified in Fig. 6, which relates the wave velocity to the soil specimen void ratio with variable water content. Different void ratios are obtained by compacting soil specimens with different compaction efforts as mentioned earlier. Fig. 6 indicates that the P wave velocity increase with decreasing void ratio, which is an expected result. Finally, it can be concluded from Figure 6 that the $\mathrm{P}$ wave velocity increases with the decrease of soil specimen water content, as previously shown in Fig. 4. 


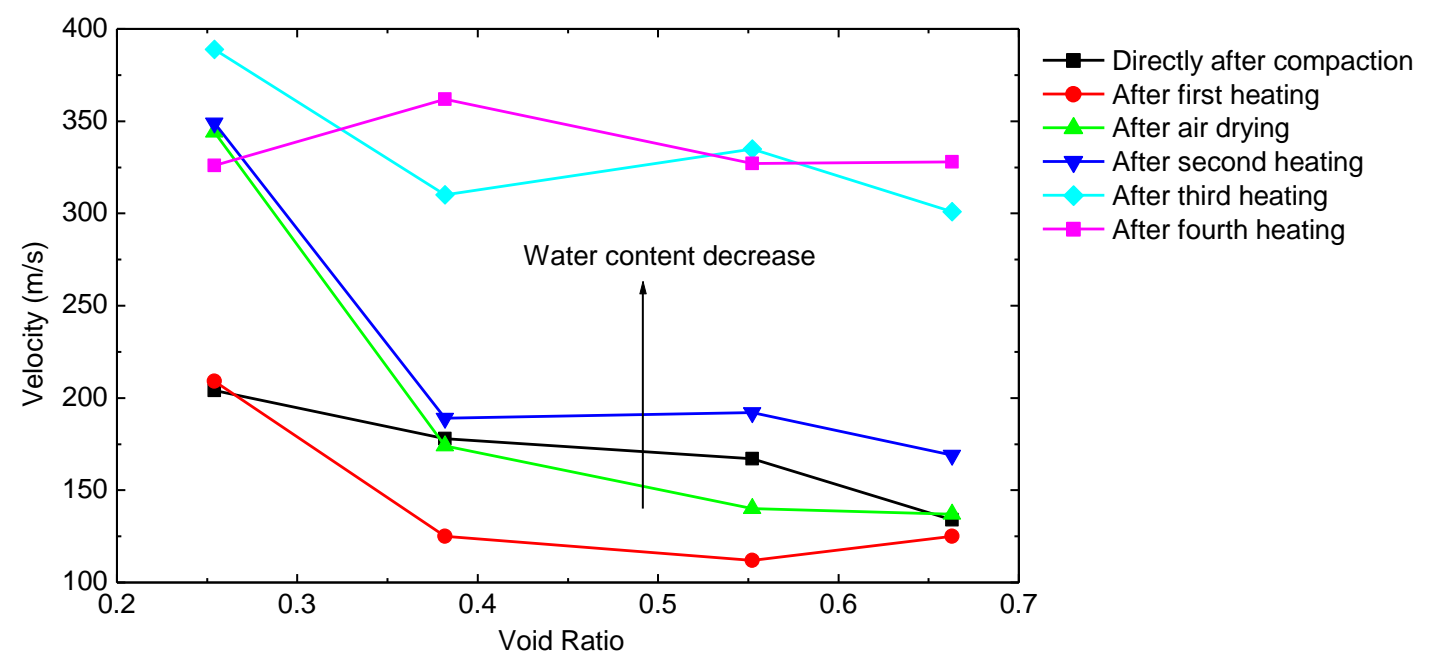

Fig. 6: Variation of P-wave velocity with void ratio, at different water content.

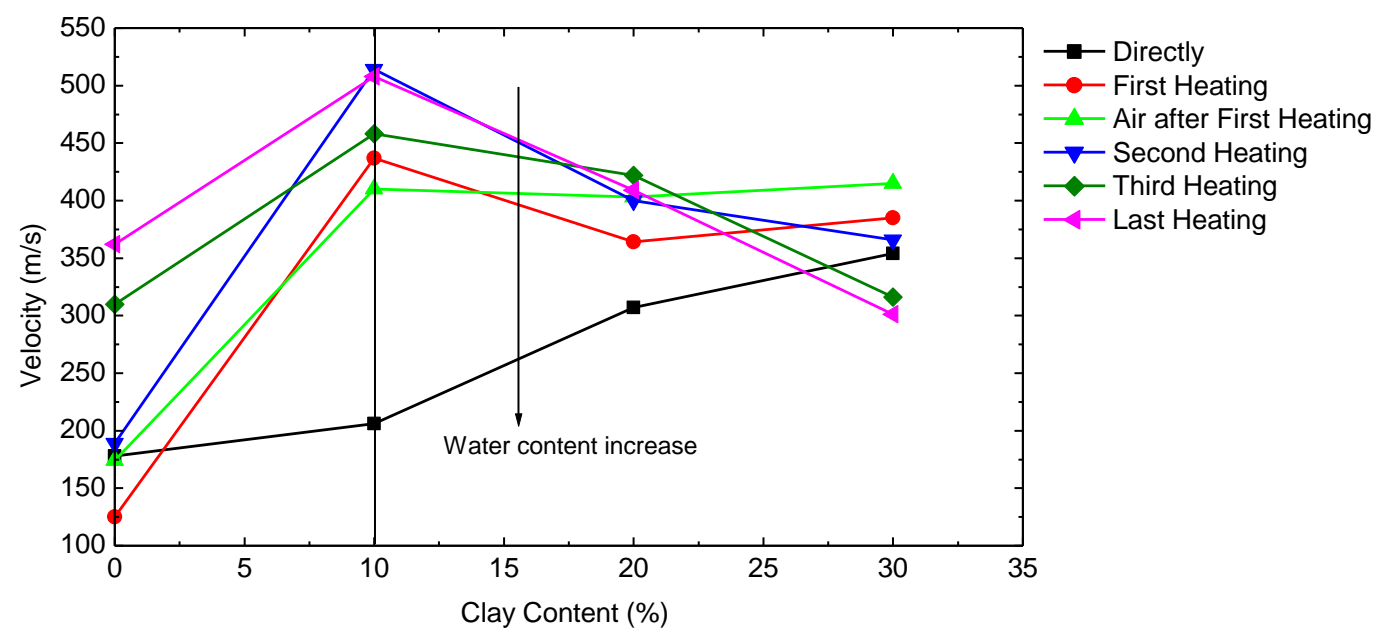

Fig. 7: Variation of P-wave velocity with soil clay contents, at different degree of dryness.

\subsection{Effect of Clay Contents}

The effect of clay content on the P-wave velocity at different drying stages is shown in Fig. 7. With the exception of the wave velocity measured directly after compaction, all other measurements at different drying stages indicate that the wave velocity increases as the clay contents increase up to $10 \%$ clay content. Once the clay contents increases beyond $10 \%$, the wave velocity started to decrease. The only exception of this conclusion is the measurement of wave velocity directly after specimen compaction, which indicates an increase of the wave velocity with clay content at all percentages of the clay. It can also been seen from Fig. 7 that the water content affects the wave velocity at different clay contents, and as the water content increases, the wave velocity decreases at most values of clay contents. It is worth noting that the void ratio of sample 2 (pure sandy soil) is e $=0.37$ while samples 8 and 9 with $10 \%$ and $20 \%$ clay contents respectively have void ratio of $\mathrm{e}=0.29$. Moreover, sample 10 with $30 \%$ clay content has a void ratio e $=0.32$. Therefore, the three samples with different clay contents show very close values of void ratio, which eliminates the void ratio as an 
effective parameter in this case. In conclusion, the variation of the P-wave velocity is not only dependent on the individual values clay content percent, but also on the water content together with clay content.

\section{Conclusion}

In this study, a number of index tests were performed in order to study the effect of different soil parameters on the sand sand $\mathrm{P}$ wave velocity. Based on the results of these index tests, the following important outcomes are worth noting:

1. Generally, P-wave velocity of sandy soil decreases with increasing water content and degree of saturation up to threshold values. Beyond these threshold values, wave velocity started to increase. The water content threshold value ranges between $3.75 \%$ to $4.5 \%$, and the degree of saturation threshold values start at $20 \%$ for lightly compacted specimen to $50 \%$ for heavily compacted specimen.

2. Void ratio of the soil specimens decreases as the compaction effort increases, and thus the soil wave velocity increases.

3. P-wave velocity increases as the soil gradation becomes finer, or when the soil fine content percent increases. This is usually accompanied by a reduction in the soil void ratio.

4. Regardless of the soil gradation, the wave velocity decreases with the water content and degree of saturation percent, up to threshold values, where the velocity starts to show slight increase. Value of saturation threshold increases as the soil fine content percent increases, or as the soil grading curve moves towards the finer side of the grain size distribution.

5. The effect of compaction effort on wave velocity is similar to the effect of fine contents, as both lead to a change in void ratio and hence a change in wave velocity.

6. The contamination of sand with clay contents significantly increases the P-wave velocity up to $10 \%$ clay content. This conclusion is true for degree of saturation less than $30 \%$. Once the clay content increases beyond $10 \%$ and/or the degree of saturation increases beyond 30\%, wave velocity starts to decrease. In conclusion, the effect of the clay content on the wave velocity also depends on the water content and degree of saturation.

\section{Acknowledgements}

The authors are grateful for funding provided by the office of research and graduate studies at American University of Sharjah, UAE (FRG14-2-19) granted to the first author.

\section{References}

[1] M. Jamiolkowski, "Role of Geophysical Testingin Geotechnical Site Characterization," 2012.

[2] Sirikarn Narongsirikul, "rock physics/ reservoir geophysics/ geomechanics," Oslo, Ph.D. Candidate 2013.

[3] Minsu Cha and Gye-Chun Cho, "Shear Strength Estimation of Sandy Soils Using Shear Wave Velocity," Geotechnical Testing Journal, vol. 6, no. 30, pp. 1-12, 2007.

[4] T. Ohkubo and Terasaki A. "Physical property and seismic wave velocity of Rocks," Japan: OYO Corporation, 1976.

[5] M. Amaral, A. Vianada Fonseca, M. Arroyo, G. Cascante, J. M. Carvalho, "Compression and shear wavep ropagation in cemented-sandspecimens," Géotechnique Letters 1 (ICE Publication), 2011.

[6] J. A. Pineda, M. Arroyo, E. Romero, E. E. Alonso. "Dynamic tracking of hydraulically induced claystone degradation," in Proceedings of the $4^{\text {th }}$ Int. Symp. on Deformation Characteristics of Geomaterials, 2008. IOS Press, pp. 809-817.

[7] J. C. Santamarina, K. A. Klein, and M. A. Fam, "Soils and Waves", John Wiley \& Sons. 2001. Chichester, UK.

[8] Marjanovic, J. "The Study of Shear and Longitudinal Velocity Measurments of Sands and Cohesive Soils," Master's Thesis, Massachusetts Institue of Technology, Cambridge, MA, USA.

[9] V. Jovicic, M. R. Coop, M. Simic, "Objective criteria for determining Gmax from bender element tests" Geotechnique, vol. 46, no. 22, pp. 357-362, 1996.

[10] L. P. Suwal and R. Kuwano, "Disk shaped piezo-ceramic transducer for $P$ and $S$ wave measurement in a laboratory soil specimened piezo-ceramic transducer for $\mathrm{P}$ and $\mathrm{S}$ wave measurement in a laboratory soil specimen," Soils and Foundations, vol. 53, no. 4, pp. 510-524, 2013. 